\title{
Sistem Informasi Penjualan Batu AKIK Berbasis Web
}

\author{
Suminten ${ }^{1}$, Rani $^{2}$, Amri $^{3}$ \\ ${ }^{1}$ Program Studi Sistem Informasi, Fakultas Teknologi Informasi, Universitas Bina Sarana Informatika PSDKU Bogor \\ ${ }^{2}$ Fakultas Ekonomi \& Bisnis, Universitas Bina Sarana Informatika Jakarta \\ ${ }^{3}$ Fakultas Teknologi Informasi Universitas Bina Sarana Informatika \\ Email: suminten.center@gmail.com ${ }^{1}$, rani.rxa@bsi.ac.id², amri@gmail.com ${ }^{3}$
}

\begin{abstract}
Abstrak
Batu yang saat ini banyak masyarakat kenal adalah Batu Akik, batu akik memiliki keunikan dan keistimewaan tersendiri, sehingga banyak batu akik yang ingin dimiliki orang banyak. Batu akik yang kini banyak dijumpai oleh masyarakat luas, itu mempengaruhi hasrat para pedagang batu akik untuk meningkatkan omset penjualan mereka. Masalah utama yang dihadapi penjual yaitu sistem yang digunakan masih manual seperti pembuatan laporan sering terjadi kesalahan dalam penjumlahan harga maupun batu yang terjual, sehingga jumlah batu yang terjual dengan jumlah harganya sering kali tidak sesuai dengan hasil yang sebenarnya. Dengan adanya masalah pokok tersebut, maka akan dibangun sebuah aplikasi penjualan berbasis web dengan menggunakan metode pengembangan perangkat lunak model waterfall dengan tahapan analisa, desain, pengkodean serta pengujian dan metode pengumpulan data yang meliputi observasi dan studi literatur. Aplikasi yang akan dibangun terdiri dari alur sistem yang meliputi pengelolaan pemesanan barang, stok barang, pembayaran, pengiriman barang dan laporan penjualan. Diharapkan dengan sistem ini kegiatan operasional penjualan batu akik dapat lebih efektif dan efisien sehingga diharapkan memberikan keuntungan finansial yang lebih bagi pemilik usaha dan memudahkan pelanggan dalam melakukan pembelian secara online tanpa datang langsung ke toko.
\end{abstract}

Kata Kunci: Analisis, Penjualan, Batu Akik, Berbasis Web

\section{Abstract}

The stone that many people today know is Agate, agate has its own uniqueness and privileges, so many agates that many people want to have. Agate which is now commonly found by the wider community, it affects the desire of agate traders to increase their sales turnover. The main problem faced by sellers is that the system used is still manual, such as making reports, there are often errors in the sum of prices and stones sold, so the number of stones sold at the total price often does not match the actual results. With these main problems, a web-based sales application will be built using the waterfall model software development method with stages of analysis, design, coding and testing and data collection methods that include observation and study of literature. The application that will be built consists of a flow system that includes managing goods orders, stock items, payments, delivery of goods and sales reports. It is expected that with this system the operational activities of agate sales can be more effective and efficient so that it is expected to provide more financial benefits for business owners and facilitate customers in making purchases online without coming directly to the store.

Keywords: Analysis, Sales, Agate, Web Based

\section{PENDAHULUAN}

Saat ini sebagian masyarakat Indonesia demam mengoleksi batu. Batu yang saat ini banyak masyarakat kenal adalah Batu Akik, karena batu akik memiliki keunikan dan keistimewaannya yang tersendiri, sehingga banyak sekali batu akik yang ingin dimiliki oleh orang banyak. Batu akik yang kini banyak dijumpai oleh masyarakat luas, itu mempengaruhi hasrat para pedagang batu akik untuk meningkatkan omset penjualan mereka. Ditengah kesibukan para penjual batu akik, kebanyakan dari mereka selalu saja ada masalah dalam pekerjaannya. Seperti halnya dalam pembuatan laporan sering terjadi kesalahan dalam penjumlahan harga maupun batu yang terjual, sehingga jumlah batu yang terjual dengan jumlah harganya sering kali tidak sesuai dengan hasil yang sebenarnya.

Itu disebabkan karena penjual masih menggunakan sistem yang manual.Sistem manual yang mereka gunakan itu seperti halnya dalam pembuatan laporan masih menggunakan pembukuan. Adapun pengakuan dari pihak pembeli, ketika pembeli ingin mengunjungi sebuah took batu akik dan berminat membeli batu akik, terkadang pembeli kehabisan stok batunya. Adapula ketika pembeli ingin membeli batu apa yang pembeli inginkan, terkadang penjual tidak menjual barang apa yang pembeli inginkan. Itu disebabkan karena tidak adanya informasi dari penjual kepada pembeli [1].

Ditengah kemajuan zaman ini, sudah banyak para pengusaha atau penjual memanfaatkan media teknologi, terutama teknologi internet berbasis website, dimana segala pekerjaan dan informasi yang diinginkan bias dengan mudah dan cepat diperoleh [2].

Menurut [3] "saat ini para pengusaha sudah banyak yang memanfaatkan media internet sebagai sarana penginformasian produk yang dijual serta perbaikan pelayanan pelanggan, hal tersebut dilakukan semata-mata untuk meningkatkan omset penjualan mereka".

Seperti halnya dengan penjual batuakik, yang pasti juga memerlukan data yang akurat, sehingga bias mengurangi terjadinya kesalahan. Disampingitu pula, penjual bias mengembangkan usahanya melalui internet, seperti memasarkan produknya, memberikan informasi yang terkait kepada pelanggan, sampai melakukan transaksi di internet. Dengan adanya internet, pembeli bahkan lebih mudah dalam mencari sesuatu apa yang diinginkannya, tidak perlu lagi pergi ke toko untuk membeli batu akik, cukup dengan membuka situs penjualan batu akik dan bias langsung memesan, barang pun bias langsung diantar ketika sudah melalui proses transaksi pembayaran [4]. 
Berdasarkan fakta yang penulis amati, inti dari permasalahan penjualan batu akik ini masih banyak penjual yang menggunakan sistem manual, seperti halnya pembuatan laporan masih menggunakan pembukuan, sehingga pekerjaan masih sering terjadi kesalahan, dan kurangnya informasi dari penjual kepada pembeli mengenai jenis batu akik apa yang dipasarkan oleh penjual. Oleh karena itu, penulis mencoba membuat program aplikasi penjualan batu akik berbasis website untuk membantu mengurangi masalah yang ada pada penjualan batu akik.[5]

Untuk membuat sistem penjualan batu akik yang berbasis web agar membantu masyarakat dalam mencari informasi seputar batu akik dengan mudah.Mengimplementasikan aplikasi e-commerce ini untuk masyarakat luas yang mempunyai kendala dalam keterbatasan waktu, penghematan biaya serta tenaga.

\section{TEORI}

Seiring dengan kemajuan teknologi informasi, menyebabkan masyarakat dunia mengenal suatu teknologi yang dinamakan Internet.Transaksi dalam dunia internetdisebut e-commerce, dimana $e$-commercemenurut [4]adalah "pembelian, penjualan dan pemasaran barang serta jasa melalui system elektronik. Seperti televise, radio dan jaringan komputer atau internet.

Internet (Interconected Network), menurut [6], adalah jaringan komputer yang menghubungkan antar jaringan secara global, internet juga disebut dengan jaringan dalam suatu jaringan yang luas.

Web Browser menurut [6] , adalah aplikasi perangkat lunak yang digunakan untuk mengambil dan menyajikan sumber informasi web. Sumber informasi web diidentifikasi dengan Uniform Resource Identifier (URI) yang dapat terdiri dari halaman web, video, gambar, ataupun konten lainnya[7].

Web Server menurut [6], adalah sebuah komputer yang terdiri dari perangkat keras dan perangkat lunak. Secara bentuk fisik dan cara kerjanya perangkat keras web server tidak berbeda dengam komputer atau PC, yang membedakan adalah kapasitas dan kapabilitasnya. Perbedaan tersebut dikarenakan Web Server bekerja sebagai penyedia layanan yang dapat diakses oleh banyak pengguna, sehingga kebutuhan kapasitas dan kapabilitas yang besar dibandingkan PC. Dukungan perangkat lunak sangat dibutuhkan agar web server dapat berjalan secara optimal.

World Wide Web (W3) atau yang lebih dikenal juga dengan istilah www, menurut [8], adalah suatu sistem yang berkaitan dengan dokumen digunakan sebagai media untuk menampilkan teks, gambar, multimedia, dan lainnya pada jaringan internet[9].

Website, menurut [10], adalah keseluruhan halaman-halaman web yang terdapat dalam sebuah domain yang mengandung informasi [11].

\section{METODE PENELITIAN}

a. Observasi

Melakukan pengamatan secara online dengan mengamati web-web yang sudah ada dan offline dengan datang langsung ke toko-toko yang menjual batu akik.

b. Analisa

Menganalisa masalah dan pemecahan masalah, menganalisa kebutuhan pengguna, menganalisa biaya yang digunkan untu membuat sistem, menganalisa kebutuhan hardware dan software. c. Desain

Merancang basis data menggunkan Entity Relathionship Diagram dan Logical Record structure, merancang struktur navigasi dan merancang interfacenya.

d. Pengkodean

Implementasi program dengan menggunakan software dreamweaver, web server xampp, dan web browser. Bahasa pemrograman yang digunakan meliputi php, html, java script, mysql, css. e. Pengujian

Black box testing yang digunakan untuk menguji alur sistem seperti register, login, order, stok barang, dan laporan.

\section{ANALISA DAN PEMBAHASAN}

\subsection{Rancangan}

Perancangan basis data menghasilkan pemetaan table-tabel yang digambarkan dengan Entity Relationship Diagram (ERD).

a. Entity Relationship Diagram 


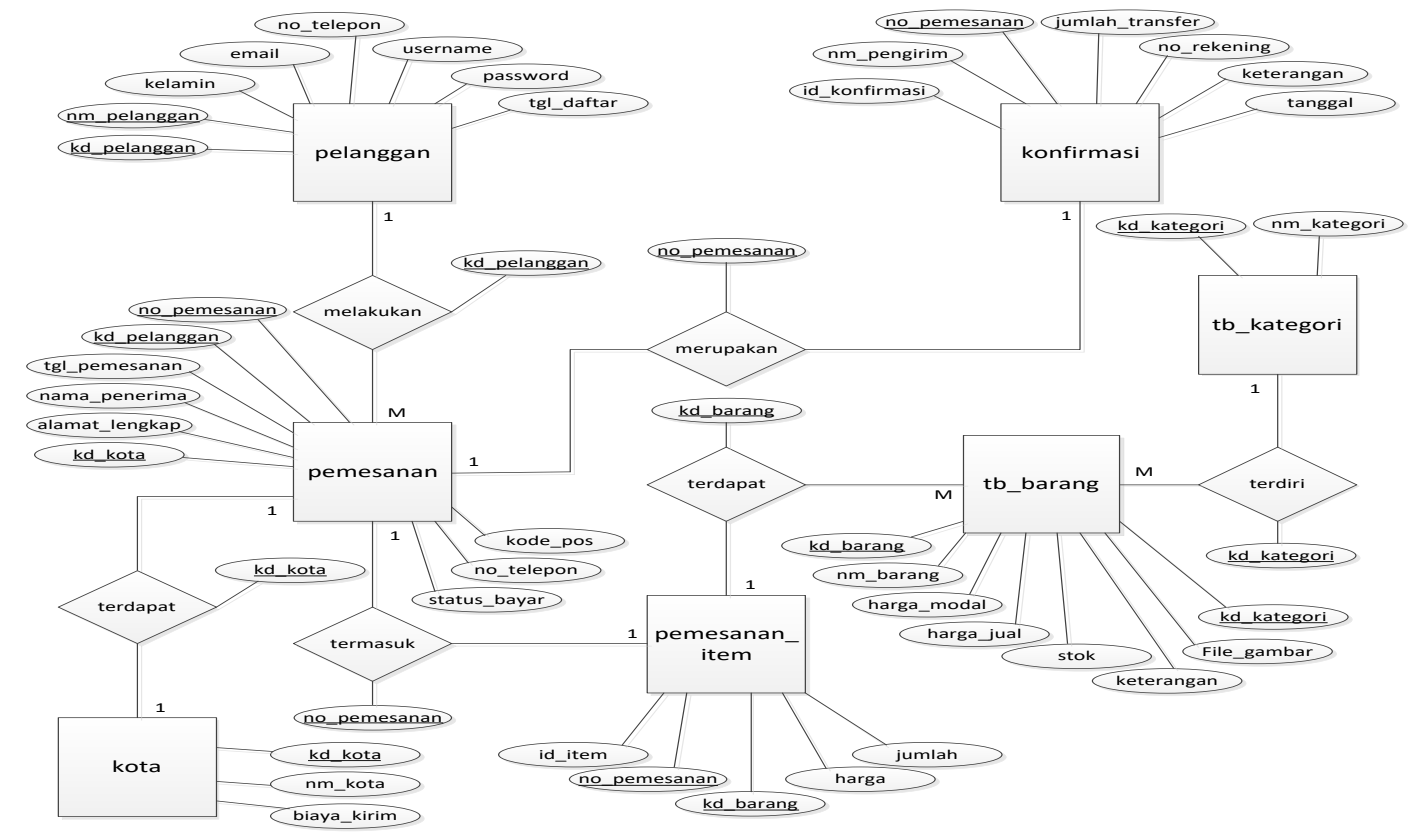

Gambar 1. Entity Relationship Diagram

\section{b. Logical Relational Structure (LRS)}

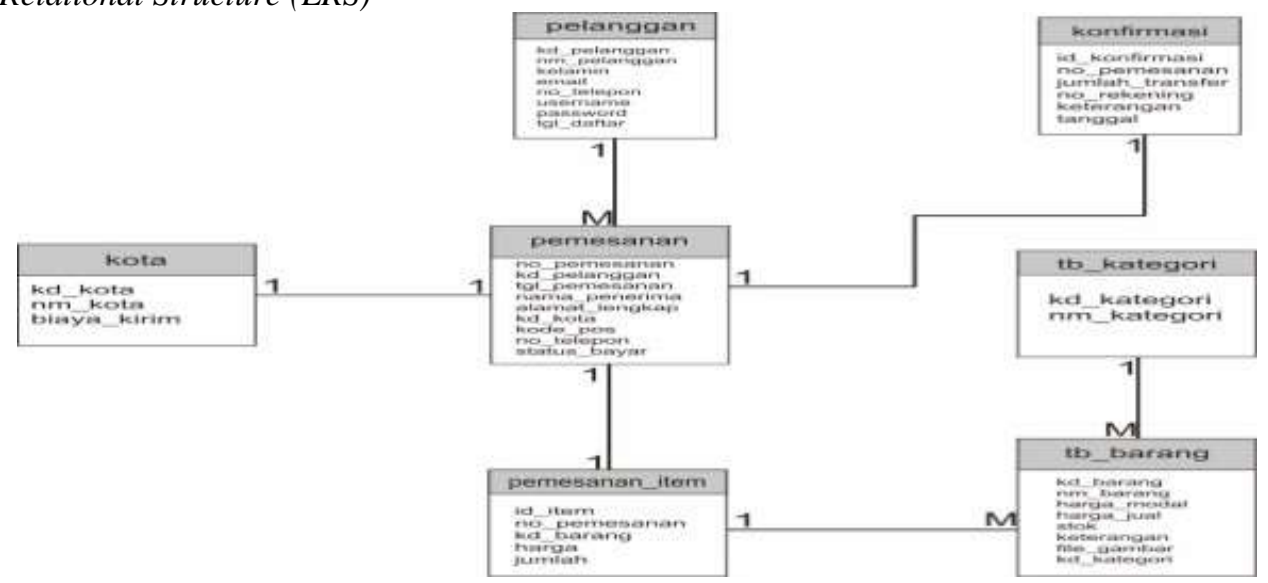

Gambar 2. Logical Relational Structure (LRS)

c. Rancangan Struktur Navigasi

Terdapat dua jenis struktur navigasi yang ada dalam sebuah website. Struktur navigasi tersebut adalah Front End yang merupakan alur kerja sistem dibagian user seperti member atau pengunjung dan juga Back End yang merupakan alur kerja sistem dibagian admin.

1. Tampilan Back End Halaman Admin

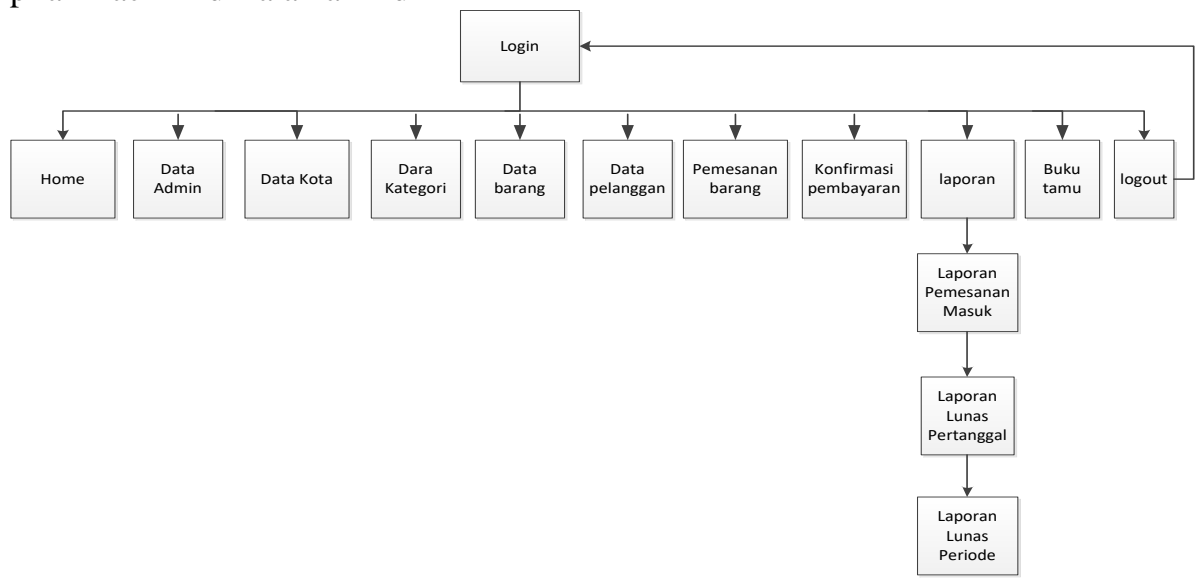

Gambar 3.Tampilan Back End Halaman Admin 
2. Tampilan Front End Halaman Pengunjung

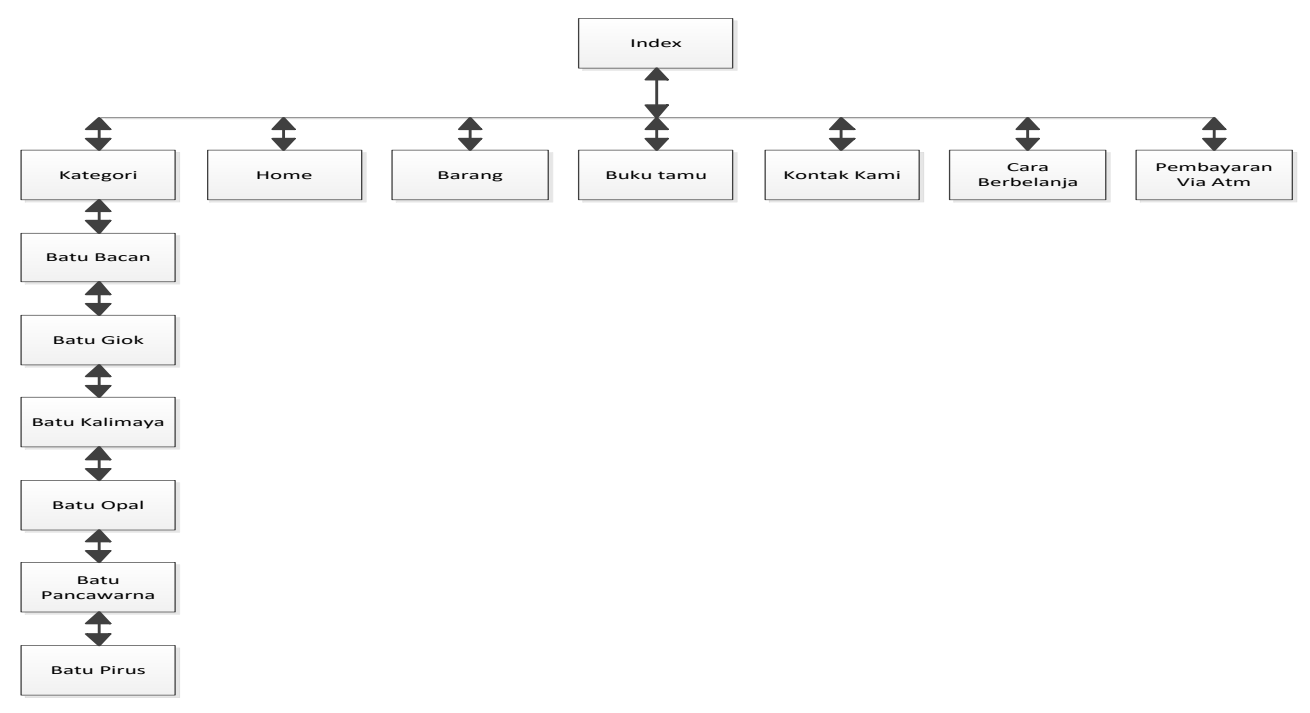

Gambar 4. Tampilan Front End Halaman Pengunjung

3. Tampilan Front End Halaman Member

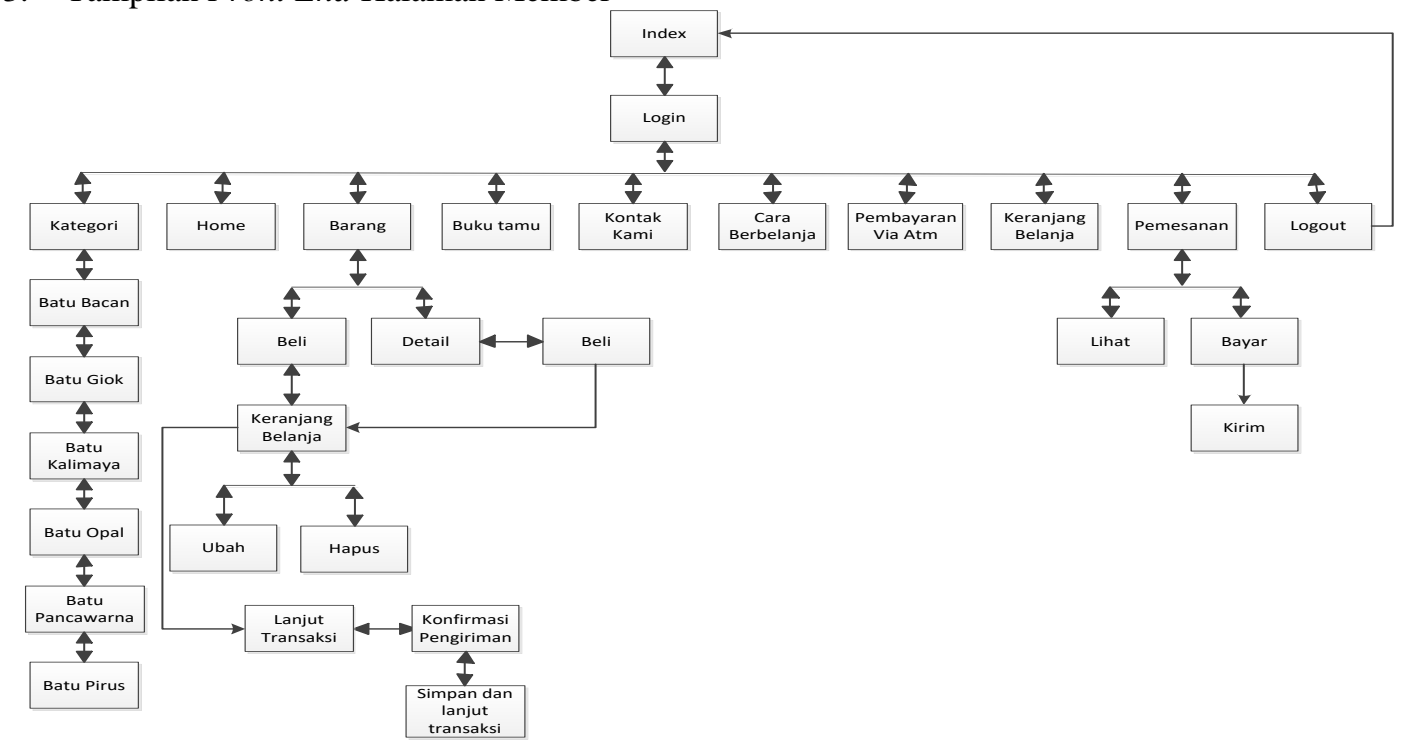

Gambar 5. Tampilan Front End Halaman Member

\subsection{Implementasi}

a. Halaman Home Depan

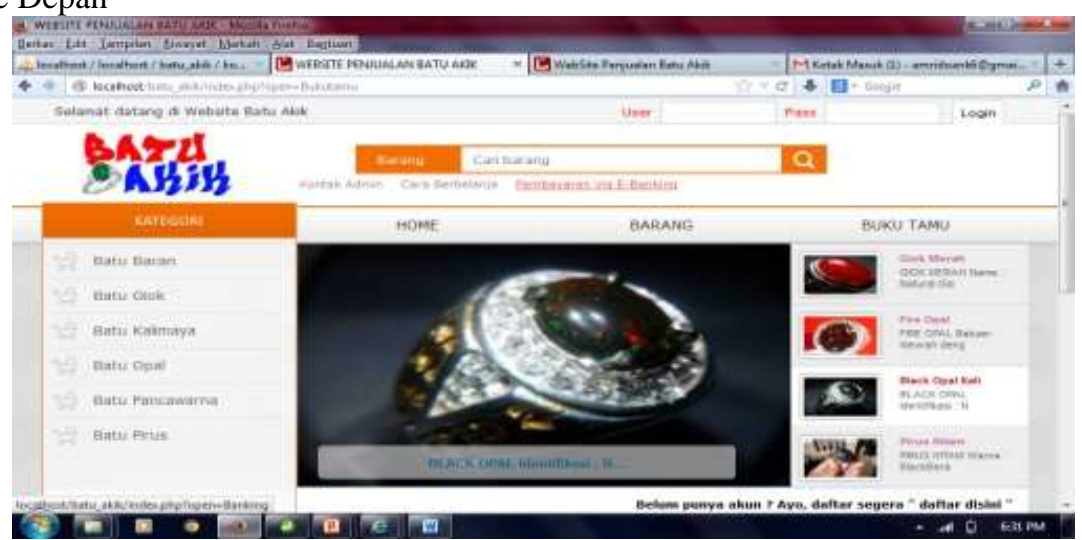

Gambar 6. Halaman Home Depan 
JURNAL MEDIA INFORMATIKA BUDIDARMA, Vol 3, No 4, Oktober 2019

ISSN 2614-5278 (media cetak)

ISSN 2548-8368 (media online)

Hal 414-421 | DOI: 10.30865/mib.v3i4.1532

b. Halaman Login Member

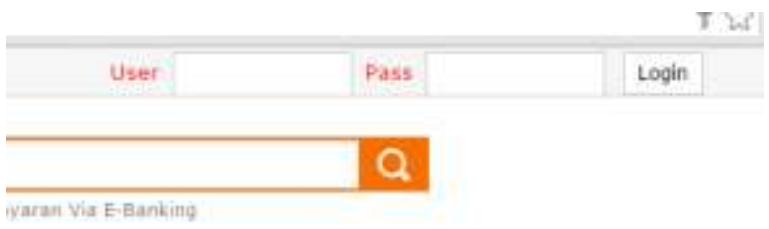

Gambar 7. Halaman Login Member

c. Halaman Member Ketika Sudah Masuk Login

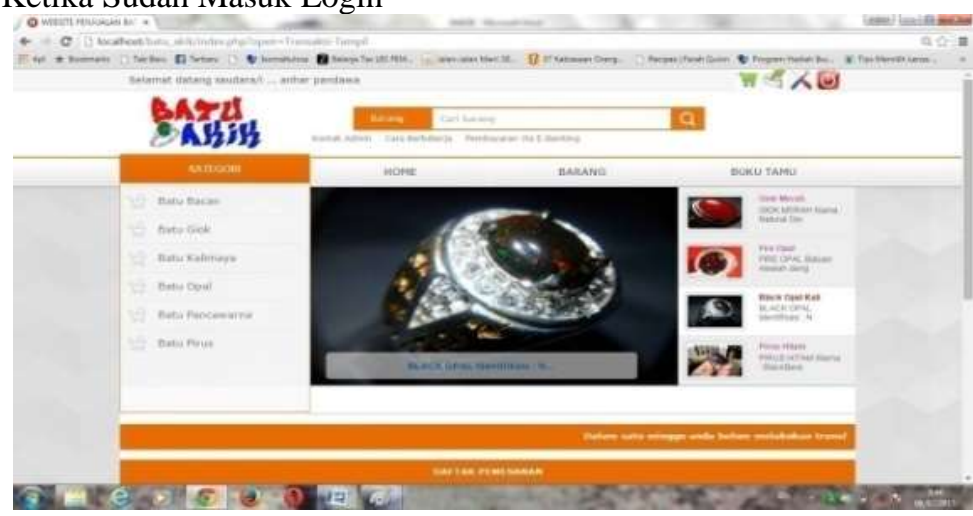

Gambar 8. Halaman Member Ketika Sudah Login

d. Halaman Pengaturan Member

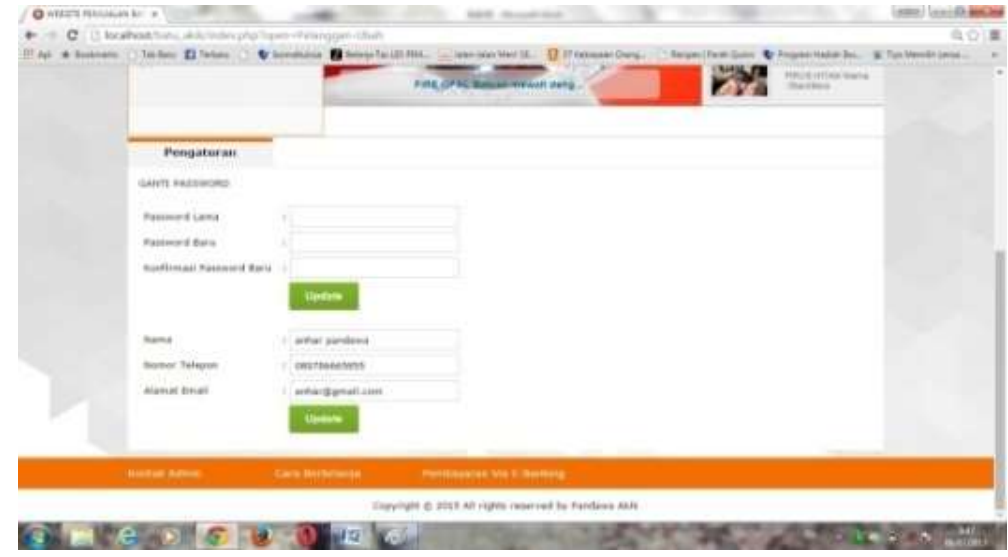

Gambar 9. Halaman Pengaturan Member

e. Halaman Buku Tamu

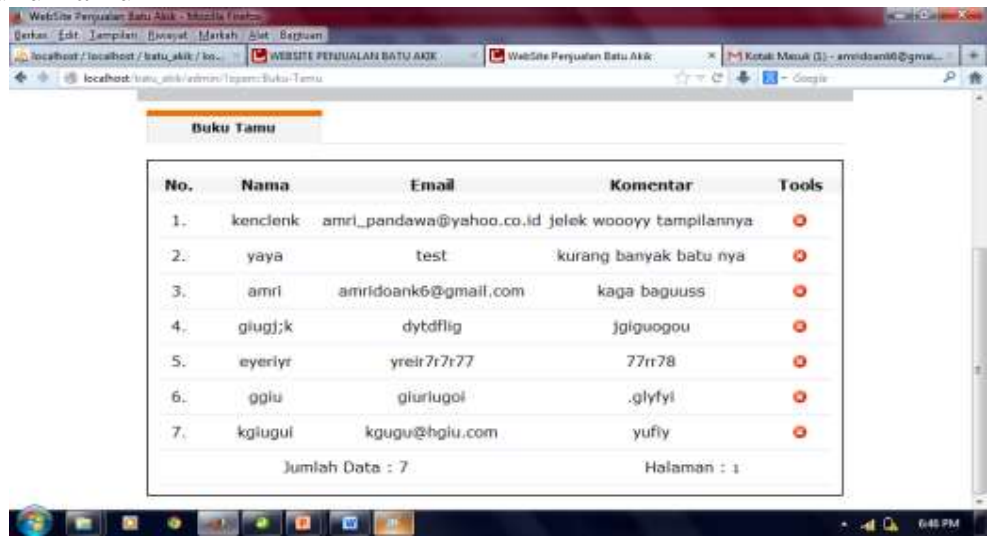

Gambar 10. Halaman Buku Tamu

f. Halaman Untuk Login ke Akun Internet Banking 


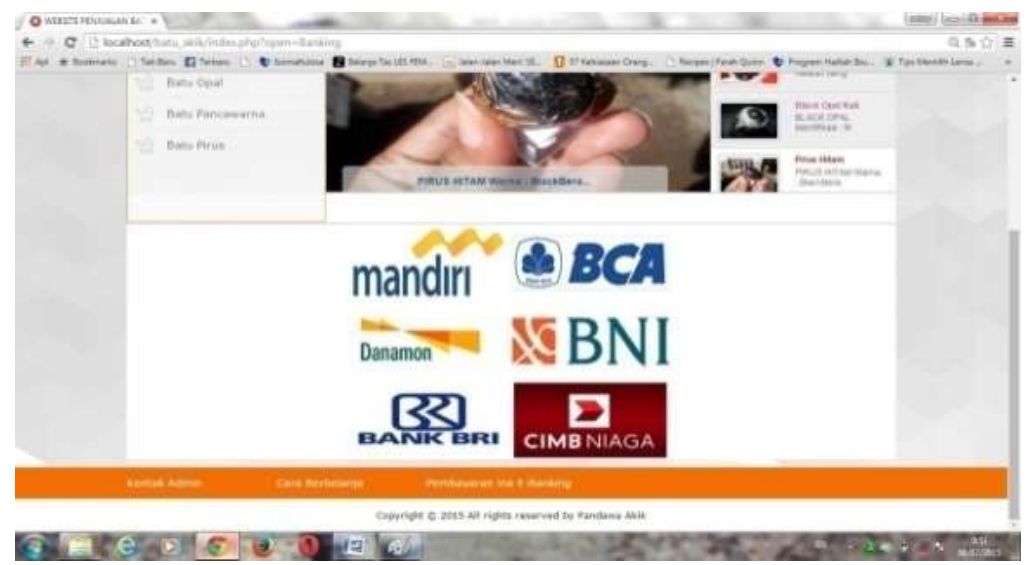

Gambar 11. Halaman Untuk Login ke Akun Internet Banking

g. Halaman Detail Barang
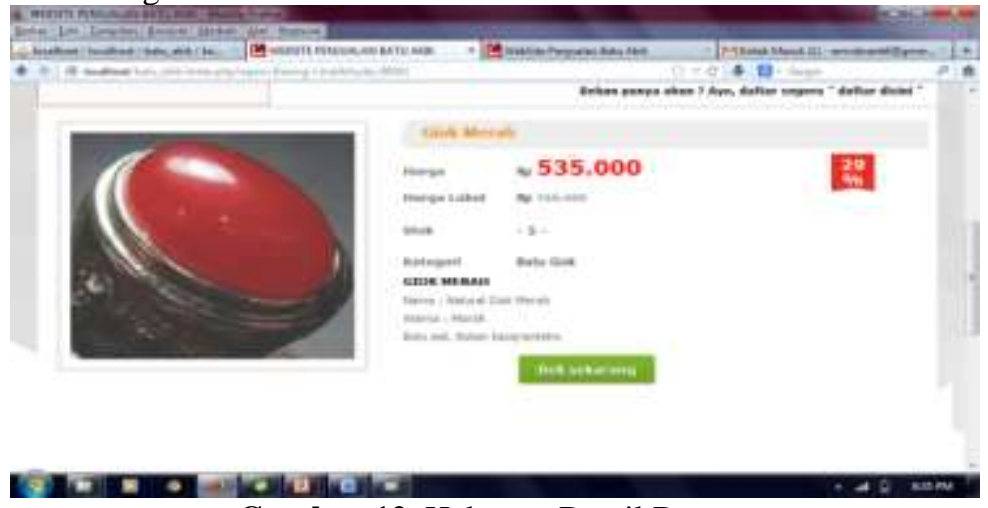

Gambar 12. Halaman Detail Barang

h. Halaman Keranjang Belanja

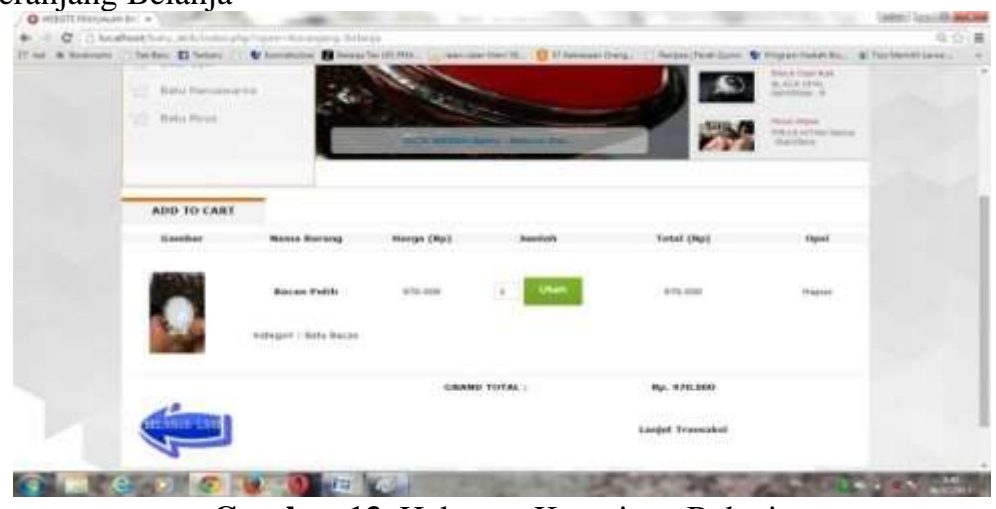

Gambar 13. Halaman Keranjang Belanja

i. Halaman From Pengiriman Alamat Lengkap

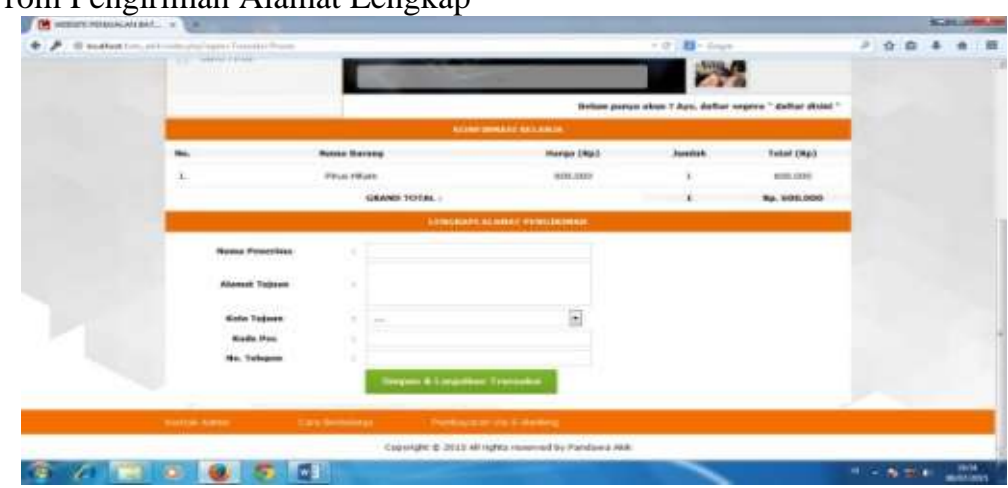

Gambar 14. Halaman From Pengiriman Alamat Lengkap

j. Halaman Daftar Riwayat Pemesanan 


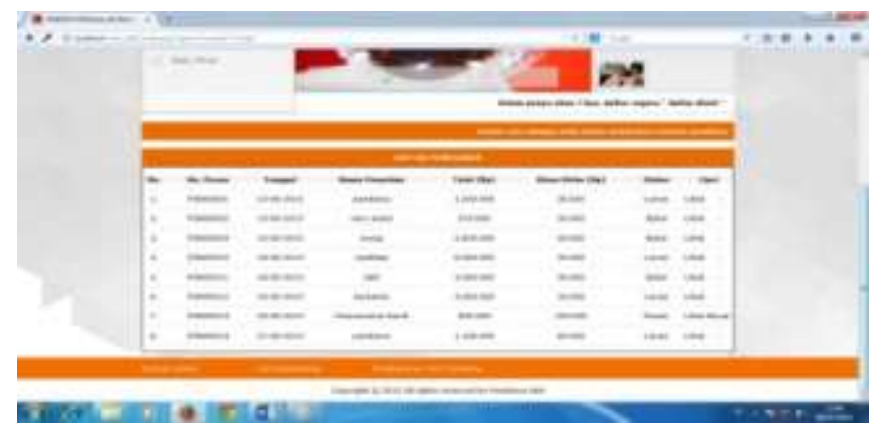

Gambar 15. Halaman Daftar Riwayat Pemesanan

k. Halaman Pendaftaran Baru

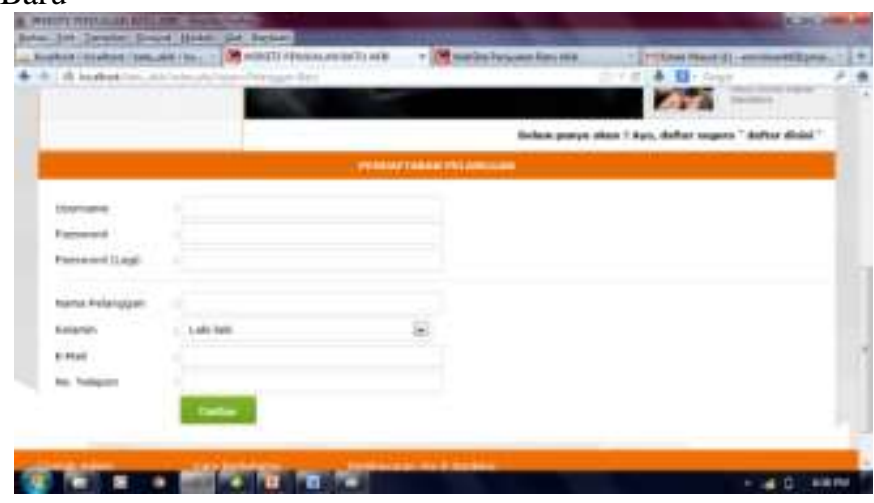

Gambar 16. Halaman Pendaftaran Baru

1. Halaman Daftar Barang

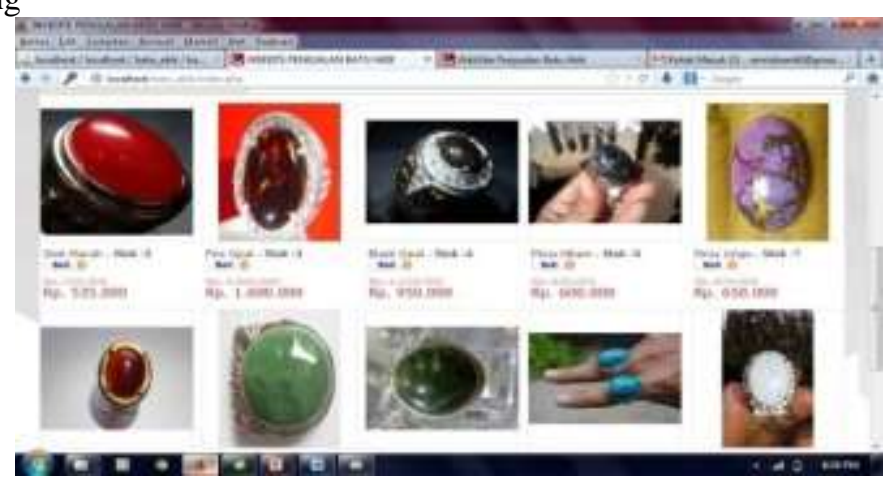

Gambar 17. Halaman Daftar Barang

m. Halaman Detail Barang Sejenis
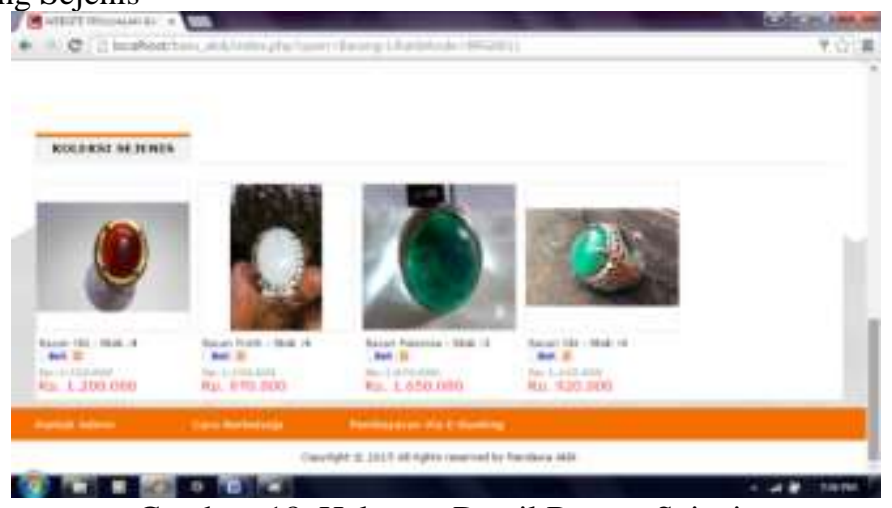

Gambar 18. Halaman Detail Barang Sejenis

\section{KESIMPULAN}

Penerapan sistem infomasi penjualan batu akik berbasis web ini bertujuan untuk mendapatkan informasi yang terkait dengan penjualan, sehingga tidak perlu lagi datang langsung ke toko penjualan batu akik. Berikut ini 
beberapa kesimpulan yang dapat penulis ambil, yaitu :a.Pengunjung tidak perlu lagi datang langsung ke toko untuk mencari dan mendapatkan informasi actual seputar barang yang diinginkannya.b.Pengunjung bisa mengetahui informasi seputar barang-barang yang ada di website penjualan batu akik. c. Pengunjung dapat melihat harga barang yang dijual didalam website penjualan batu akik..d. .Administrator (admin) bertugas mengatur website informasi penjualan seperti mengelola data barang, data member dan memastikan server website tetap hidup.e. MySql sebagai server database untuk aplikasi PHP. Kemudahannya dalam integrasi ke berbagai aplikasi web (terutama PHP) cukup membantu dalam pengembangan sistem informasi penjualan batu akik secara online.f. Dalam teknologi pemrograman aplikasi berbasis web yang telah dikembangkan, PHP dapat dijadikan sebagai salah satu pilihan utama dalam pembuatan aplikasi berbasis web karena keunggulannya dan kemudahan dalam pemakaiannya.

\section{REFERENCES}

[1] Martha, Aplikasi Penjualan ONline. 2015.

[2] I. Sabil, Strategi Penjualan dan Pemasaran. 2010.

[3] A. W. Sigit, Website Super Canggih dengan Plugin jQuery Terbaik. 2011.

[4] Wong, E-Commerce dan Strategi Penjualan Online. 2010.

[5] Macdoms, Dreamweaver CS5 dengan PHP dan MySQL untuk pemula. 2011.

[6] Siberio, Internet dan Aplikasinya. 2013.

[7] J. Enterprise, Panduan Praktis Menguasai pemrograman Web dengan Javascript. 2011.

[8] Jogiyanto, Sistem teknologi Informasi. 2009.

[9] M. R. Arief, Pemrograman Web Dinamis menggunakan PHP dan MySQL. 2011.

[10] R. A. Sukamto and M. Shalahuddin, Rekayasa Perangkat Lunak Terstruktur dan Berorientasi Objek . 2013.

[11] A.-B. Bin ladjamudin, Analisis dan Desain Sistem Informasi. 2015. 